\title{
Satisfação e percepção dos usuários dos sistemas de saneamento de municípios goianos operados pelas prefeituras
}

\author{
Satisfaction and users perception regarding the sanitation systems of \\ municipalities in the state of Goiás operated by the local governments
}

\author{
Aline Souza Carvalho Lima', Paulo Sérgio Scalize², \\ Poliana Nascimento Arruda ${ }^{3}$, Luis Rodrigo Fernandes Baumann ${ }^{4}$
}

口-

\begin{abstract}
RESUMO
Conhecer a satisfação dos consumidores em relação aos serviços de saneamento configura-se como ferramenta capaz de auxiliar a gestão desses serviços. Este trabalho avaliou a satisfação dos consumidores a respeito dos serviços de saneamento básico gerenciados diretamente pelas prefeituras em 21 municípios do estado de Goiás. Para a avaliação da satisfação, no que diz respeito às características detodos os componentes do saneamento,foi utilizadaaescalaintervalar.Procedeu-se à verificação da percepção dos consumidores em relação à realidade das condições de saneamento comparando os resultados obtidos por meio de formulários com as condições constatadas nas visitas aos órgãos municipais responsáveis pelo saneamento básico. Para tanto, foram aplicados 479 formulários a pessoas escolhidas aleatoriamente, e o número de formulários aplicados em cada município foi obtido utilizando a regra de alocação de Neyman. Verificou-se que a satisfação prevalece para abastecimento de água, coleta e transporte de resíduos. Porém, para drenagem urbana, disposição final dos resíduos e todos os indicadores referentes ao esgotamento sanitário, prevalece a insatisfação. Pequena parcela da população manifestou-se como indiferente, mostrando a preferência dos consumidores em se posicionar. Observou-se que a percepção dos consumidores condiz com a realidade dos municípios, o que pôde ser verificado durante a realização das visitas.
\end{abstract}

Palavras-chave: saneamento; consumidor; água; esgoto; resíduo sólido; drenagem urbana.

\begin{abstract}
Meet consumer satisfaction as sanitation services is a tool to assist in their management. This study evaluated consumer satisfaction regarding the sanitation services directly managed by local governments of 21 municipalities in the state of Goiás. In the evaluation of satisfaction with the characteristics of all sanitation components, we used the interval scale. We verified the perception of consumers in relation to the reality of sanitation by comparing the results in the forms with the conditions observed in visits to municipal agencies responsible for sanitation. To that, 479 forms were applied with the people selected at random, and the number of forms used in each city was obtained using the Neyman allocation rule. It was found that satisfaction prevails for water supply, collection and transportation of waste. However, dissatisfaction prevails for urban drainage, waste disposal and all indicators relating to sewage. Small portion of the population is expressed as indifferent, showing consumer preference in positioning. It was observed that the perception of consumers was consistent with the reality of the municipalities perceived during the visits.
\end{abstract}

Keywords: sanitation; consumer; water; sewage; solid waste; urban drainage.

\section{INTRODUÇÃO}

São inúmeros os tipos de prestação de serviços públicos existentes nas mais diversas áreas, como Saúde, Educação, Transporte, Lazer, Saneamento Básico, entre outras. Em razão das mudanças ocorridas

em escala global nas últimas décadas, do acesso à informação e do acúmulo de conhecimento, as exigências relacionadas à qualidade da prestação dos serviços oferecidos aumentaram. Segundo Lage (2008), os cidadãos estão cada vez mais informados e conscientes dos direitos

口-

'Mestre em Engenharia do Meio Ambiente pela Universidade Federal de Goiás (UFG) - Goiânia (GO), Brasil.

${ }^{2}$ Mestre e Doutor em Hidráulica e Saneamento pela Escola de Engenharia de São Carlos da Universidade de São Paulo (EESC-USP). Professor associado na Escola de Engenharia Civil e Ambiental (EECA) da UFG - Goiânia (GO), Brasil.

3Doutoranda em Ciências Ambientais pela UFG - Goiânia (GO), Brasil.

${ }^{4}$ Doutor em Estatística pela Universidade de São Paulo (USP). Professor adjunto do Instituto de Matemática e Estatística da UFG - Goiânia (GO), Brasil. Endereço para correspondência: Paulo Sérgio Scalize - Escola de Engenharia Civil e Ambiental da Universidade Federal de Goiás - Avenida Universitária, 1488 - Lote Área Bloco A - sala 14 - 74605-220 - Setor Universitário - Goiânia (GO), Brasil - E-mail: pscalize.ufg@gmail.com

Recebido em: 18/11/14 - Aceito em: 03/11/16 - Reg. ABES: 142945 
que possuem, e isso tem influenciado no empenho e nos esforços dos prestadores de serviços.

Uma das formas de se conhecer a qualidade dos serviços públicos é mediante o emprego da pesquisa de satisfação. Por meio dessa, é possível avaliar se o cliente está satisfeito com os serviços e identificar os problemas proeminentes, a fim de procurar a melhor forma de solucioná-los (AKINBOADE et al., 2012; BADRI et al., 2015).

As pesquisas sobre satisfação dos clientes ganharam força na década de 1970, época em que ocorreu a primeira conferência a respeito da satisfação/insatisfação do consumidor nos Estados Unidos, no ano de 1976 (ALVES, 2003). Essas pesquisas consistem em um sistema de administração de informações que continuamente ouve o consumidor por meio da avaliação do desempenho da empresa ou do serviço. Além disso, indicam os caminhos para as decisões futuras de comercialização e marketing (ROSSI \& SLONGO, 1998).

A falta de competitividade influencia diretamente a qualidade do serviço público. Enquanto o setor privado recebe pelo que oferece e investe recursos humanos e financeiros para conseguir o maior número possível de consumidores, devido à necessidade de competir com os prestadores de serviços do mesmo ramo, o setor público oferece serviços que devem contemplar todos os cidadãos. Portanto, os serviços públicos são essenciais ao bem-estar das pessoas, devendo servi-las sem objetivo de lucro, uma vez que os pagamentos feitos em formas de taxas e tarifas visam à manutenção e ao aperfeiçoamento de cada setor (BRASIL, 1997).

Nesse sentido, Galvão Júnior e Paganini (2009) esperam que a regulação nos termos da Lei $\mathrm{n}^{\circ} 11.445$, de 5 de janeiro de 2007, que estabelece diretrizes nacionais para o saneamento básico, contribua diretamente para a introdução de mecanismos de eficiência nesse setor, assegurando qualidade e preços mais acessíveis, além de maior eficácia das ações voltadas para a melhoria das condições de salubridade e bem-estar social.

A prestação do serviço público de saneamento básico, principalmente em municípios operados por instituições locais — administração direta, autarquias ou empresas multimunicipais - , carece de estudo, requerendo, portanto, maior atenção. As principais pesquisas que avaliam a satisfação dos consumidores acerca dos serviços de abastecimento de água e esgotamento sanitário são aquelas realizadas pelas próprias empresas de saneamento. Essas empresas utilizam como instrumentos de pesquisa formulários temáticos de satisfação, a fim de avaliar os próprios serviços prestados, alimentando o banco de dados referente à qualidade, objetivando a melhoria contínua (ARSESP, 2013). Podem ainda avaliar outros itens, como a capacidade de pagar pelo serviço (VARELA, 2016), a utilização de indicadores (VON SPERLING \&VON SPERLING, 2013), os benefícios da educação ambiental (ORTIZCORREA et al., 2016), entre outros.
As informações obtidas por meio das pesquisas de satisfação abrangem vários serviços públicos e privados, e indicam aos formuladores de políticas públicas quais são os pontos que mais influenciam na satisfação e na qualidade de vida da população e que, por sua vez, estão deficientes. Montenegro e Costa (1999) verificaram o grau de satisfação dos consumidores com relação à empresa de saneamento de Brasília (Companhia de Saneamento Ambiental do Distrito Federal - CAESB), com o objetivo de conhecer as falhas apontadas pelos consumidores e melhorar a qualidade da prestação desse serviço. Os resultados obtidos foram positivos para a empresa. Ainda assim, os consumidores apontaram algumas falhas, como: erros nas contas; baixa qualidade da água; problemas de comunicação com o serviço de atendimento ao cliente; demora na resolução de problemas relacionados às redes de água ou esgoto; e falhas na realização de obras. Após tomar conhecimento desses problemas, a empresa iniciou o planejamento das atividades necessárias para saná-las. Badri et al. (2015) compararam as informações obtidas por meio de questionários aplicados à população do estado de Abu Dhabi, nos Emirados Árabes, nos anos de 2009 e 2013, avaliando 17 serviços locais, entre eles saneamento, água e eletricidade. Foi possível concluir que os serviços tidos como essenciais não foram decisivos para o aumento do índice de satisfação do cidadão, mas serviços como estacionamento e táxi tiveram um peso maior. Os autores pontuaram que novos modelos de avaliação da satisfação do consumidor sejam desenvolvidos, visando a um olhar mais integrador quanto às necessidades dos clientes. No Brasil, Martini et al. (1999) pesquisaram o grau de percepção da população da grande Florianópolis, Santa Catarina, acerca da qualidade da água, aplicando questionários em bairros de diferentes classes sociais, escolhendo residências aleatoriamente. Esse estudo possibilitou o levantamento de informações fundamentais para o município, evidenciando a importância da participação popular.

Além da iniciativa governamental de conhecer o nível de satisfação do consumidor quanto aos serviços públicos prestados, a população detém papel fundamental na busca por melhorias dos serviços que se encontram deficientes. Akinboade et al.(2012) realizaram uma pesquisa de satisfação em três distritos da África do Sul e pontuaram que no ano de 2010 houve protestos referentes a deficiências na prestação de serviços públicos, como falta de água, energia, coleta de lixo, despejos, má administração, entre outras. Nesse contexto, vários governos do país passaram a implementar esse tipo de instrumento.

A Empresa Municipal de Água e Resíduos de Vila Real, em Portugal, também avaliou a satisfação de seus clientes, com vistas à melhoria da qualidade do serviço oferecido. Além disso, o estudo analisou a percepção dos funcionários e líderes da empresa utilizando três questionários diferentes para os sujeitos estudados - clientes, 
funcionário e líderes. Ao final, verificou-se que os respondentes mostraram visão positiva com relação ao serviço, ratificando a ideia de que esse tipo de pesquisa pode ser utilizado como ferramenta de análise para investimentos em processo de melhoria dos serviços prestados (LAGE, 2008).

O caráter participativo da população é de fundamental importância, visto que a Lei $\mathrm{n}^{\circ} 11.445 / 2007$ tem como princípio a participação popular no processo de elaboração dos Planos Municipais de Saneamento Básico por meio de audiências ou consultas públicas (BRASIL, 2007). Esse princípio ratifica a necessidade de verificar a satisfação e a percepção dos consumidores no que diz respeito aos serviços utilizados. Em Goiás, observa-se a falta de pesquisas nessa área.

A área de Saneamento do estado de Goiás cresceu nos últimos anos, porém ainda existem municípios sem acesso ao esgotamento sanitário e ao abastecimento público de água tratada. De acordo com o Panorama Nacional de Saneamento Básico (BRASIL, 2011), cerca de $31 \%$ da população do estado tem acesso a condições satisfatórias de abastecimento de água, esgotamento sanitário e manejo de resíduos sólidos, quantidade pequena se comparada ao Distrito Federal, onde $70 \%$ da população tem acesso a esses serviços. Nos estados da região Centro-Oeste, menos de $5 \%$ da população não tinha acesso ao sistema de abastecimento de água até 2008. Com relação ao esgotamento sanitário, Mato Grosso do Sul e Goiás apresentavam os piores índices, o primeiro e terceiro lugar respectivamente, com mais de $76 \%$ da população sem acesso a esses serviços (BRASIL, 2011).

Quanto à forma de gestão do saneamento, existem no país, atualmente, três categorias prestadoras de serviços de água e esgoto, a saber: locais, privadas ou estaduais/regionais. Os prestadores de serviços locais são as autarquias, os órgãos da administração direta ou empresa multimunicipal — pública ou de economia mista —, formados pelos Serviço Autônomo de Água e Esgoto (SAAEs) e Departamento Autônomo de Água e Esgoto (DAAEs). As empresas estaduais/regionais atendem $78 \%$ da população. São exemplos: a Saneago, em Goiás; a Sabesp, em São Paulo; a Embasa, na Bahia; e a Cedae, no estado do Rio de Janeiro (MOGAMI, 2013).

Diante do exposto, esta pesquisa teve por objetivo verificar o grau de satisfação dos consumidores relativamente aos sistemas de saneamento gerenciados diretamente pelas prefeituras em 21 municípios do estado de Goiás. Espera-se, com isso, que este estudo venha a se configurar como documento de consulta para gestores municipais e profissionais da área de Saneamento, auxiliando-os nos processos de tomada de decisão e planejamentos futuros, contribuindo, desse modo, para o desenvolvimento sanitário, com vistas à melhoria da qualidade de vida da população.

\section{MATERIAL E MÉTODOS}

Este estudo foi realizado em 21 municípios, de um total de 246, localizados no estado de Goiás. Essas localidades foram escolhidas por apresentarem serviços de saneamento básico gerenciados diretamente pelas prefeituras. No total, o número de habitantes dos municípios pesquisados representa 6,67\% da população do estado, totalizando 400.909 habitantes. Segundo o Censo do Instituto Brasileiro de Geografia e Estatística (IBGE 2010), Goiás possui 6.003.788 habitantes, com densidade demográfica de 17,65 hab. $\mathrm{km}^{2}$, sendo o estado mais populoso da região Centro-Oeste. Na Figura 1, é apresentada a distribuição espacial dos 21 municípios, sua população segundo dados do Censo (IBGE, 2010) e o número de formulários aplicados aos munícipes de cada localidade.

Para a recolha de dados, foram aplicados formulários aos consumidores durante a realização de visitas aos municípios, no período de março de 2013 a março de 2014.

No tocante à realidade das condições de saneamento, a verificação da percepção dos consumidores foi realizada por meio da comparação entre os resultados dos formulários e as condições constatadas nas visitas aos órgãos municipais responsáveis pelo saneamento básico.

O formulário foi submetido e aprovado pelo Comitê de Ética da Universidade Federal de Goiás (UFG), sob o Parecer nº 391.907/2013. Doze questões compuseram o formulário, as quais versaram sobre a satisfação e a percepção do consumidor quanto aos serviços de abastecimento de água (quatro questões), esgotamento sanitário (três questões), resíduos sólidos domiciliares (RSD) (quatro questões) e drenagem urbana (uma questão) oferecidos no município, sendo as respostas anotadas no próprio formulário, conforme orientado por Marconi e Lakatos (1992).

Tendo em vista a verificação da percepção dos consumidores quanto à realidade dos serviços de saneamento básico, observou-se a relação entre suas respostas e o apresentado pela realidade. Para o sistema de abastecimento de água (SAA), foram utilizadas três características organolépticas - o gosto, o cheiro e a limpidez além da satisfação dos consumidores com relação ao sistema como um todo. Procedeu-se da mesma forma em relação ao sistema de esgotamento sanitário (SES), por meio de questões acerca da rede coletora e do tratamento do esgoto. A avaliação da satisfação quanto aos RSD foi realizada contemplando os serviços de coleta, transporte e sua disposição final. Por fim, a Drenagem Urbana foi avaliada por meio de uma questão de satisfação, a qual englobava o sistema como um todo.

Para avaliar a satisfação quanto às características de todos os componentes do saneamento, utilizou-se a escala intervalar, com pontuações de 1 a 5, conforme recomendado por Rossi e Slongo (1998). Assim, as pontuações 1 e 2 representam insatisfação, a 3 representa 
indiferença, e a 4 e 5, satisfação. Para determinar o nível de satisfação segundo a percepção dos entrevistados, o índice adotado seguiu o método usado por Yeh e Lee (1975) apud Sarwar et al. (2006), empregando a Equação 1. Esse método também foi utilizado por Majunder et al. (2007), Al-Qadery e Muhibbullah (2008) e Ali et al. (2014) em estudos que envolveram satisfação do consumidor, e os valores variaram de $-1 \mathrm{a}+1$. Quanto mais próximo de +1 , mais satisfeitos.

$I_{S}=\frac{f_{s}-f_{i}}{N}$

Em que:

$I_{s}=$ índice de satisfação;

$\mathrm{f}_{\mathrm{s}}=$ número de entrevistados satisfeitos; $\mathrm{f}_{\mathrm{i}}=$ número de entrevistados insatisfeitos;

$\mathrm{N}$ = número total de entrevistados.

Empregou-se a Análise de Clusters, por meio do método K-médias, para formar quatro clusters (grupos) dos municípios estudados, com características semelhantes em termos do índice de satisfação. Aplicou-se a técnica para cada questão do formulário, bem como para saneamento básico em geral, por meio da avaliação das 12 questões em conjunto. $\mathrm{O}$ método K-médias baseia-se na decomposição da soma de quadrados total de uma análise de variância. Objetivou-se criar clusters com alta homogeneidade interna e alta heterogeneidade entre eles (DURAN \& ODELL, 1974).

A quantidade de respondentes foi delimitada por amostragem estratificada. Recomenda-se esse tipo de amostragem para estudos em

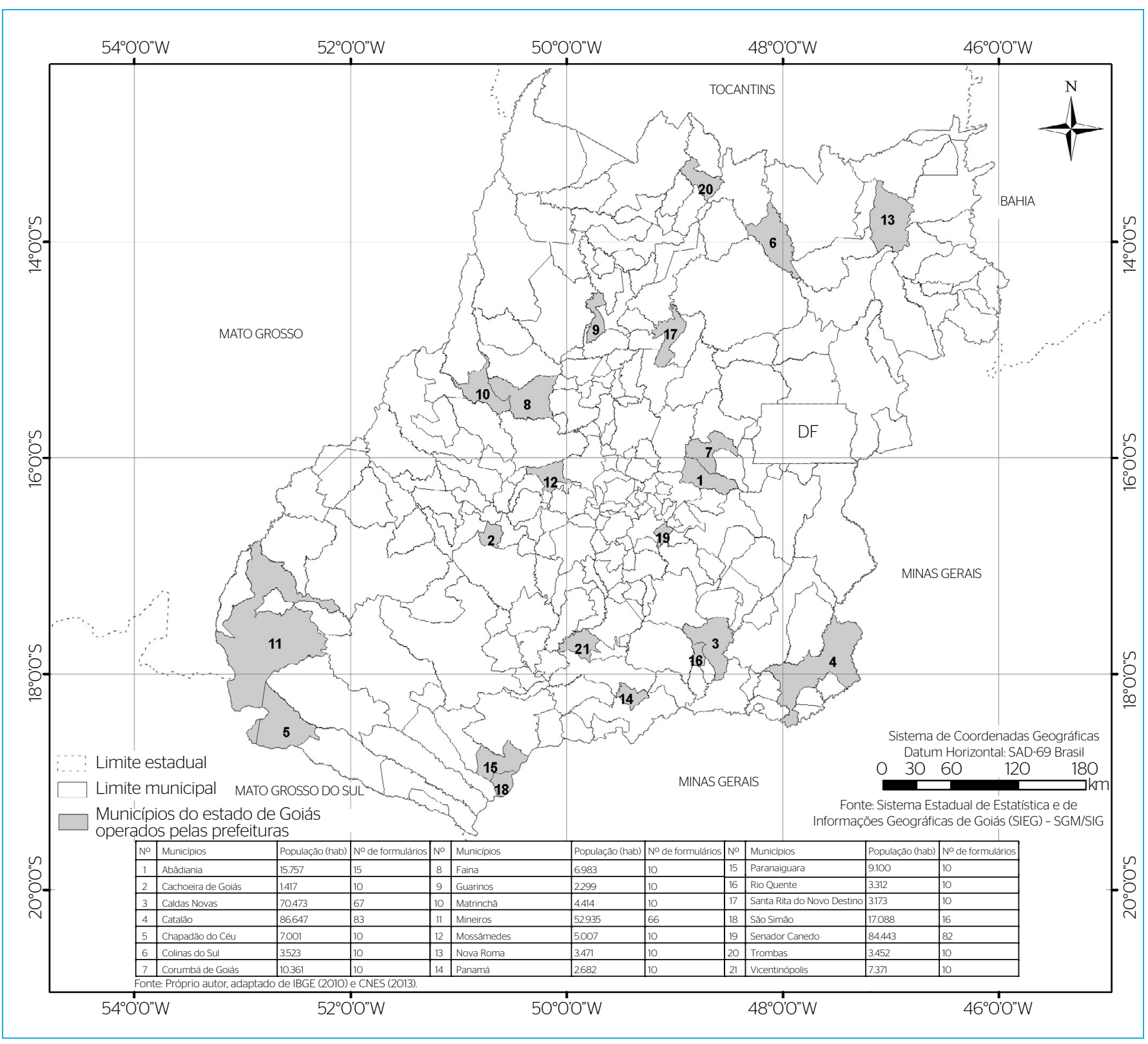

Figura 1 - Distribuição espacial dos municípios pesquisados, sua variação populacional e número de formulários aplicados aos munícipes de cada localidade. 
que as respostas apresentam comportamento homogêneo e heterogêneo dentro e entre os estratos, respectivamente. Considera-se que cada município representa um estrato e que, dentro dele, as características das respostas serão homogêneas, visto que se trata de pessoas submetidas a um mesmo prestador de serviço, refletindo pequena variação. No entanto, quando avaliada a relação entre os municípios, as amostras apresentam-se heterogêneas em função das características peculiares de cada sistema e órgão gestor, como infraestrutura; influência política e autonomia financeira. Além disso, o objetivo principal da estratificação é garantir que todos os estratos sejam pesquisados, atingindo consumidores de todas as classes (ROSSI \&SLONGO, 1998).

O cálculo da amostragem em cada município foi realizado pela Equação 2, seguindo a regra da alocação de Neyman (1934), que leva em consideração a proporção entre a população total dos estratos e a população em cada estrato. Esse método foi igualmente aplicado nos estudos de Péllico Netto e Sanquetta (1997) e Luiz et al. (2012). Em cada estrato, a escolha dos participantes para aplicação do formulário ocorreu por meio de amostragem aleatória (BADRI et al., 2015; ADANK et al., 2016) nos centros comerciais dos municípios, com o objetivo de contemplar munícipes de diferentes bairros, visto que as atividades desenvolvidas nos centros envolvem toda a população. Considerou-se o erro máximo de estimativa da proporção amostral de 5\% e o nível de confiança de $95 \%$, sendo 10 o número mínimo de formulários aplicado em cada município (Figura 1).

$n^{\star}=\frac{\sum_{h=1}^{L} N_{h}^{2} \hat{\sigma}_{h}^{2} / W_{h}}{N^{2} E^{2} / t^{2}+\sum_{h=1}^{L} N_{h} \hat{\sigma}_{h}^{2}}$

Em que:

$\mathrm{Nh}=$ tamanho do estrato $\mathrm{h}$ (população de cada município);

$\mathrm{N}$ = somatório de $\mathrm{Nh}$ (soma das populações dos municípios objeto do estudo);

$\hat{\sigma}_{h}^{2}=$ é a variância amostral no estrato h;

$\mathrm{E}=$ erro amostral; e

$\mathrm{Wh}=$ proporção de unidades amostrais no estrato $h$.

\section{RESULTADOS E DISCUSSÕES}

A forma de gestão dos serviços de saneamento de água e esgoto dos 21 municípios estudados está disposta no Quadro 1. Observa-se que a maioria dos municípios tem esses dois elementos do saneamento gerenciados por autarquias. Quanto à forma de gestão, os serviços de gerenciamento dos resíduos sólidos urbanos são oferecidos, em geral, diretamente pelas prefeituras, por meio da administração direta, das secretarias de obras e da infraestrutura e secretarias de meio ambiente.

A Figura 2 apresenta, por meio de um gráfico tipo Boxplot, as variações entre os indicadores avaliados — satisfação, indiferença e insatisfação - nos municípios. Verifica-se que, para a condição de satisfação, prevaleceram os indicadores de água, além da coleta e do transporte de resíduos (Figura 2A). Existe uma quantidade pequena da população que se mostra indiferente à situação dos indicadores analisados, com os maiores percentuais concentrados entre a faixa de 0 a $25 \%$ (Figura 2B), evidenciando que os consumidores se posicionaram como satisfeitos ou insatisfeitos. A insatisfação ocorreu quanto à disposição final dos resíduos e aos indicadores de esgoto, com destaque para o seu tratamento (Figura 2C).

O parâmetro satisfação é o que apresenta maior quantidade de valores atípicos. O município de Faina conta com um para o indicador "cheiro da água" e outro para "água geral": 20 e 10\% (Figura 2A), respectivamente - ambos valores atípicos inferiores. $\mathrm{O}$ valor atípico superior, com base no indicador "água geral", é relativo à Nova Roma, onde a água não é tratada. Para o tratamento do esgoto, foram encontrados três valores atípicos superiores: Abadiânia e Rio Quente, com 60\% de satisfação; e São Simão, com 43,8\% (Figura 2A). Em Chapadão do Céu, foi obtido um valor atípico para o indicador "esgoto geral", com $80 \%$ de satisfação (Figura 2A). O indicador "coleta dos RSD" obteve três valores atípicos superiores - Cachoeira de Goiás, Chapadão do Céu e Trombas — e dois inferiores - Colinas do Sul e Paranaiguara. O indicador "disposição final dos RSD” obteve valor atípico superior (Figura 2A) em Chapadão do Céu (90\%), sendo os resíduos do município dispostos em aterro controlado, que já foi operado e licenciado como aterro sanitário.

Na Tabela 1, são apresentadas as porcentagens de municípios em função da faixa de satisfação dos entrevistados.

\section{Sistema de abastecimento de água}

Ao observar a Figura 3, nota-se que quatro municípios apresentam índices máximos de satisfação ( $(s=1$ ) no que se refere ao gosto da água. Isso significa que $100 \%$ dos entrevistados estão satisfeitos. Os municípios são estes: Colinas do Sul, Guarinos, Nova Roma e Paranaiguara.

Quadro 1 - Tipo de gestão dos serviços de saneamento de água e esgoto.

\begin{tabular}{|c|c|c|}
\hline Autarquias & $\begin{array}{c}\text { Tipo de prestação dos serviços de água e esgoto } \\
\text { Departamento ou secretaria específica para o } \\
\text { serviço }\end{array}$ & $\begin{array}{c}\text { Departamento ou secretaria não específica para } \\
\text { o serviço }\end{array}$ \\
\hline $\begin{array}{c}\text { Abadiânia, Catalão, Chapadão do Céu, Corumbá } \\
\text { de Goiás, Faina, Matrinchã, Mineiros, Senador } \\
\text { Canedo, Trombas e Caldas Novas. }\end{array}$ & $\begin{array}{c}\text { Panamá, Rio Quente, São Simão e } \\
\text { Vicentinópolis. }\end{array}$ & $\begin{array}{c}\text { Paranaiguara, Santa Rita do Novo Destino, } \\
\text { Cachoeira de Goiás, Colinas do Sul, } \\
\text { Mossâmedes, Nova Roma e Guarinos. }\end{array}$ \\
\hline
\end{tabular}


Os três primeiros são abastecidos por mananciais superficiais, e o último, por manancial subterrâneo. Porém, nenhum deles realiza tratamento. $\mathrm{Na}$ Tabela 1, verifica-se que, para esse indicador, $80,9 \%$ dos municípios estão com satisfação acima de 50\%, e, desse total, 33,3\% encontram-se com satisfação acima de 74\%, o que pode ser observado na Figura 3. Dentre esses, Matrinchã é o único que realiza o tratamento de água. Assim, os resultados mostram que a presença do tratamento influencia diretamente a satisfação com relação ao gosto da água, isso porque os consumidores associam esse gosto à adição de cloro, fato esse constatado em outros trabalhos (SILVA et al., 2009; MILAGRES \& SAYAGO, 2012).

A relação entre tratamento da água e gosto ruim foi observada também em Mineiros. Nesse município, 15\% dos consumidores são abastecidos por água de mina com desinfecção, porém, na captação, é disponibilizado um ponto de água sem adição de cloro, que é bastante utilizado pelos consumidores. A Tabela 1 e a Figura 3 mostram ainda que 9,5\% dos municípios - Faina e Trombas - estão com satisfação abaixo de $25 \%$, e ambos contam com SAA provido de estação de tratamento de água (ETA), com instalações antigas e deficitárias.

Quanto ao cheiro da água, nota-se uma similaridade com o indicador "gosto". A Tabela 1 mostra que 85,7\% dos municípios estão com satisfação acima de 50\%. Na Figura 3, observa-se que Colinas do Sul, Guarinos e Nova Roma atingiram 100\% de satisfação; enquanto Faina, Matrinchã e Santa Rita do Novo Destino estão com satisfação abaixo de $50 \%$. O problema de gosto ou odor na água pode estar relacionado à presença de metabólitos de algas, como MIB (2-metilisoborneol) e Geosmina. Em estudo realizado em dois sistemas produtores que abastecem parte da Região Metropolitana de São Paulo, Ferreira Filoh e Alves (2006) constataram que a população apresenta maior percepção à presença de Geosmina em relação aos resultados provenientes do método analítico ou painel sensorial. Além disso, Jardine et al.(1999) afirmam que há razões substanciais para apoiar a possibilidade de que estranhos odores na água potável podem revelar a presença de substâncias que representem risco potencial à saúde.

O terceiro indicador das características organolépticas, a limpidez, obteve satisfação acima de 50\% em $81 \%$ dos municípios. Observa-se, na Figura 3, que Nova Roma apresentou novamente $100 \%$ de satisfação, acompanhado de Rio Quente. Nesses dois municípios, as captações são realizadas em mananciais superficiais, inseridas em áreas protegidas, onde a água sofre reduzida

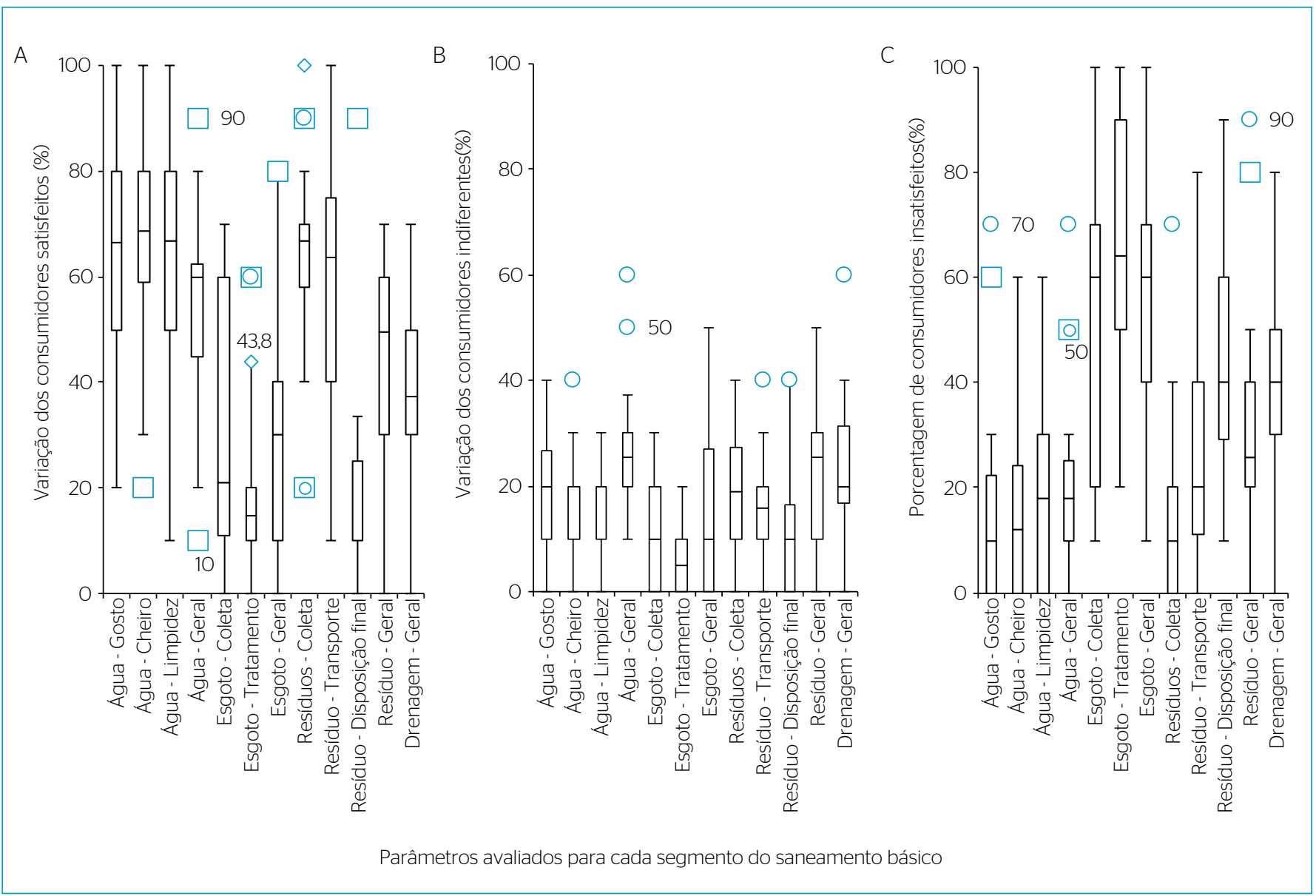

Figura 2 - Boxplot para as situações de satisfação (A), indiferença (B) e insatisfação (C) do consumidor dos municípios visitados em relação aos segmentos do saneamento. 
interferência de sólidos em períodos de chuva. Os menores índices de satisfação foram constatados nos municípios de Matrinchã, Santa Rita do Novo Destino e Trombas, ficando abaixo dos 25\%, o que está evidenciado na Figura 3. Durante a aplicação dos formulários, percebeu-se que os consumidores associavam os períodos chuvosos à qualidade, em função do aumento de "sujeira" na água, fato também observado por Silva et al. (2009) em estudo com moradores do município de Vitória, Espírito Santo. Essa percepção está relacionada a alguns parâmetros, como turbidez e cor aparente, utilizados por Rocha et al. (2006). Além disso, existem

Tabela 1 - Situações de satisfação, indiferença e insatisfação dos consumidores entrevistados.

\begin{tabular}{|c|c|c|c|c|c|c|c|c|c|c|c|c|c|}
\hline \multirow{2}{*}{ Condição } & \multirow{2}{*}{ Faixa (\%) } & \multicolumn{4}{|c|}{ SAA } & \multicolumn{3}{|c|}{ SES } & \multicolumn{4}{|c|}{ RSD } & \multirow{2}{*}{$\begin{array}{l}\text { SDU } \\
\text { Geral }\end{array}$} \\
\hline & & Gosto & Cheiro & Limpidez & Geral & Coleta & Tratamento & Geral & Coleta & Transporte & Disposição final & Geral & \\
\hline \multirow{4}{*}{ Satisfeitos } & O a 24 & 9,5 & 4,8 & 14,3 & 19,0 & 52,4 & 81,0 & 47,6 & 9,5 & 14,3 & 71,4 & 23,8 & 14,3 \\
\hline & 25 a 49 & 9,5 & 9,5 & 4,8 & 14,3 & 14,3 & 9,5 & 38,1 & 4,8 & 19,0 & 19,0 & 23,8 & 57,1 \\
\hline & 50 a 74 & 47,6 & 47,6 & 38,1 & 47,6 & 33,3 & 9,5 & 9,5 & 61,9 & 38,1 & 0,0 & 52,4 & 28,6 \\
\hline & 75 a 100 & 33,3 & 38,1 & 42,9 & 19,0 & 0,0 & 0,0 & 4,8 & 23,8 & 28,6 & 9,5 & 0,0 & 0,0 \\
\hline \multirow{4}{*}{ Indiferentes } & O a 24 & 57,1 & 81,0 & 85,7 & 47,6 & 95,2 & 100,0 & 71,4 & 66,7 & 85,7 & 85,7 & 47,6 & 61,9 \\
\hline & 25 a 49 & 42,9 & 19,0 & 14,3 & 42,9 & 4,8 & 0,0 & 23,8 & 33,3 & 14,3 & 14,3 & 47,6 & 33,3 \\
\hline & 50 a 74 & 0,0 & 0,0 & 0,0 & 9,5 & 0,0 & 0,0 & 4,8 & 0,0 & 0,0 & 0,0 & 4,8 & 4,8 \\
\hline & 75 a 100 & 0,0 & 0,0 & 0,0 & 0,0 & 0,0 & 0,0 & 0,0 & 0,0 & 0,0 & 0,0 & 0,0 & 0,0 \\
\hline \multirow{4}{*}{ Insatisfeitos } & O a 24 & 81,0 & 76,2 & 66,7 & 71,4 & 28,6 & 4,8 & 9,5 & 81,0 & 71,4 & 19,0 & 47,6 & 23,8 \\
\hline & 25 a 49 & 9,5 & 14,3 & 19,0 & 14,3 & 14,3 & 19,0 & 23,8 & 14,3 & 14,3 & 42,9 & 28,6 & 47,6 \\
\hline & 50 a 74 & 9,5 & 9,5 & 14,3 & 14,3 & 33,3 & 38,1 & 42,9 & 4,8 & 9,5 & 19,0 & 14,3 & 23,8 \\
\hline & 75 a 100 & 0,0 & 0,0 & 0,0 & 0,0 & 23,8 & 38,1 & 23,8 & 0,0 & 4,8 & 19,0 & 9,5 & 4,8 \\
\hline
\end{tabular}

SAA: sistema de abastecimento de água; SES: sistema de esgotamento sanitário; RSD: resíduos sólidos domiciliares; SDU: sistema de drenagem urbana.

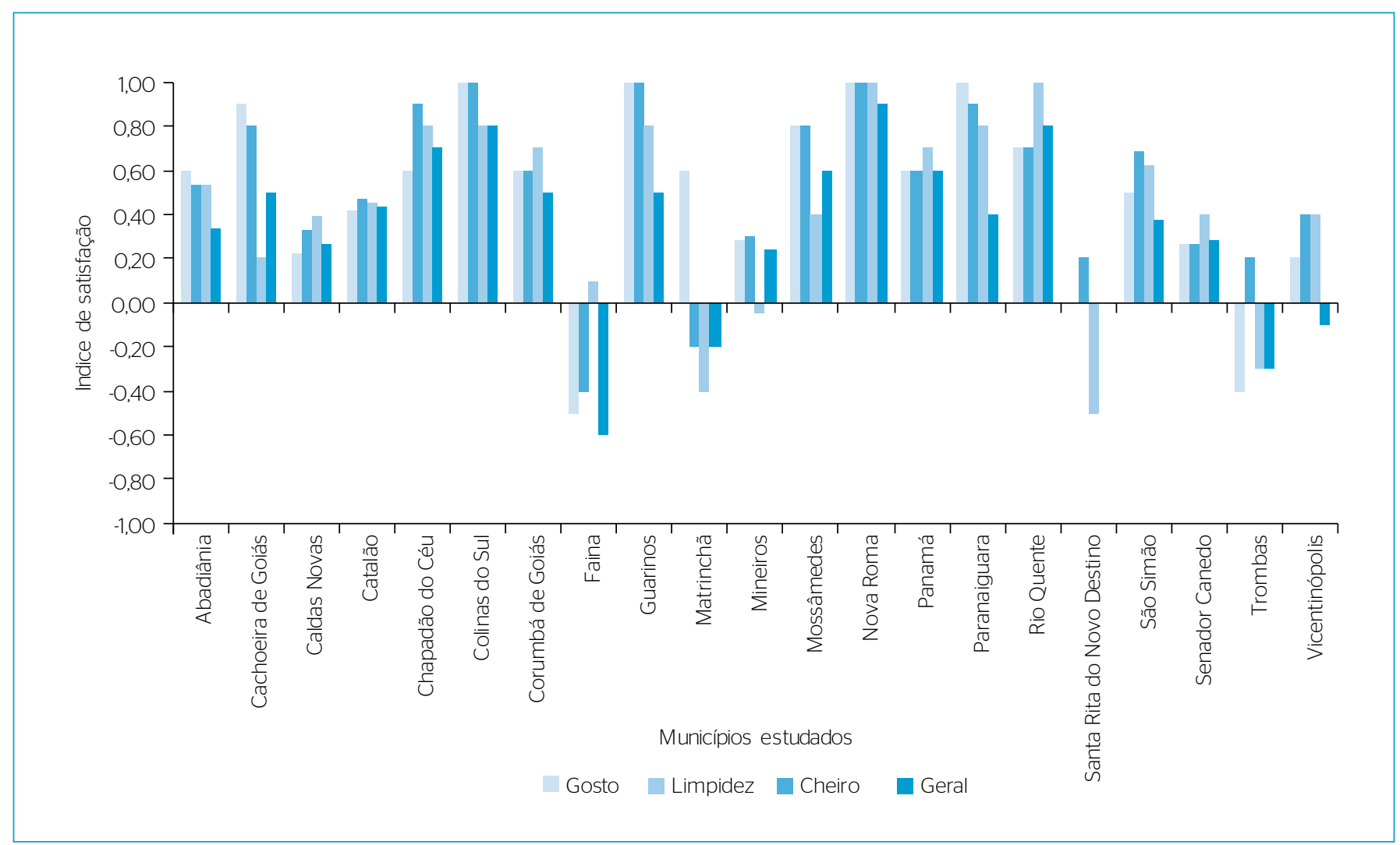

Figura 3 - Índice de satisfação em relação aos indicadores para o abastecimento de água. 
limites estabelecidos pela Portaria n ${ }^{\circ} 2.914$ do Ministério da Saúde (BRASIL, 2011).

Importa mencionar que os entrevistados refletiam para responder às questões, ponderando a pontuação e levando em consideração os períodos de seca e chuva. Isso indica que os municípios com baixos valores de satisfação não mantêm a qualidade ao longo do ano.

Quanto ao indicador "abastecimento de água geral", pode-se observar, na Tabela 1 e na Figura 3, que 67,7\% dos municípios apresentaram satisfação superior a 50\%; dentre esses, Colinas do Sul, Nova Roma, Chapadão do Céu e Rio Quente obtiveram percentuais acima de $74 \%$. Esses dois últimos são os únicos que realizam tratamento de água. Os menores percentuais de satisfação foram obtidos em Trombas, Santa Rita do Novo Destino e Faina, que apresentaram índices de satisfação abaixo de $25 \%$.

Verificou-se que os municípios que não realizam tratamento da água obtiveram, em geral, bons percentuais de satisfação, o que denota que a cultura influencia o julgamento das pessoas. Os consumidores de Cachoeira de Goiás e Mossâmedes consideram a água desses municípios como importante recurso sagrado, além de ser mineral. Essa ideia acerca da água também foi apontada por Kuhnen et al.(2009) e Ribeiro e Galizone (2003). Além disso, os moradores dessas localidades não se interessam na implantação do tratamento de água, mostrando a falta de preocupação com a qualidade do produto que consomem, o que também foi verificado por Rocha et al. (2006). Esse fato ratifica a necessidade de trabalhos voltados à educação, à conscientização dos cidadãos sobre a importância da saúde pública, com a implantação de tratamentos que tornem a água própria para o consumo. Conforme Queiroz et al. (2009), as informações obtidas servem para alertar sobre possíveis intervenções, tanto pelo serviço de abastecimento de água como pelo Poder Público, atendendo aos padrões de potabilidade preconizados pelas legislações vigentes, pois a qualidade da água pode influir no aparecimento de doenças diarreicas.

Apesar das questões relacionadas principalmente à qualidade da água, que requer melhor tratamento, o índice de satisfação para o SAA foi o maior entre os quatro segmentos do saneamento, atingindo $+0,45$, em uma escala de $-1,0$ a $+1,0$.

\section{Sistema de esgotamento sanitário}

Em geral, os municípios obtiveram percentuais altos de insatisfação acerca da coleta e do tratamento de esgoto. No total, $66,7 \%$ dos municípios apresentaram consumidores com satisfação abaixo dos $50 \%$ quanto à coleta do esgoto (Figura 4). A insatisfação pode ser explicada pela ausência de rede coletora de esgotos e pela falta de tratamento destes.

Para o indicador "tratamento de esgoto", 85,7\% dos municípios apresentaram satisfação abaixo de 50\% (Figura 4), e 9,5\%, entre 50

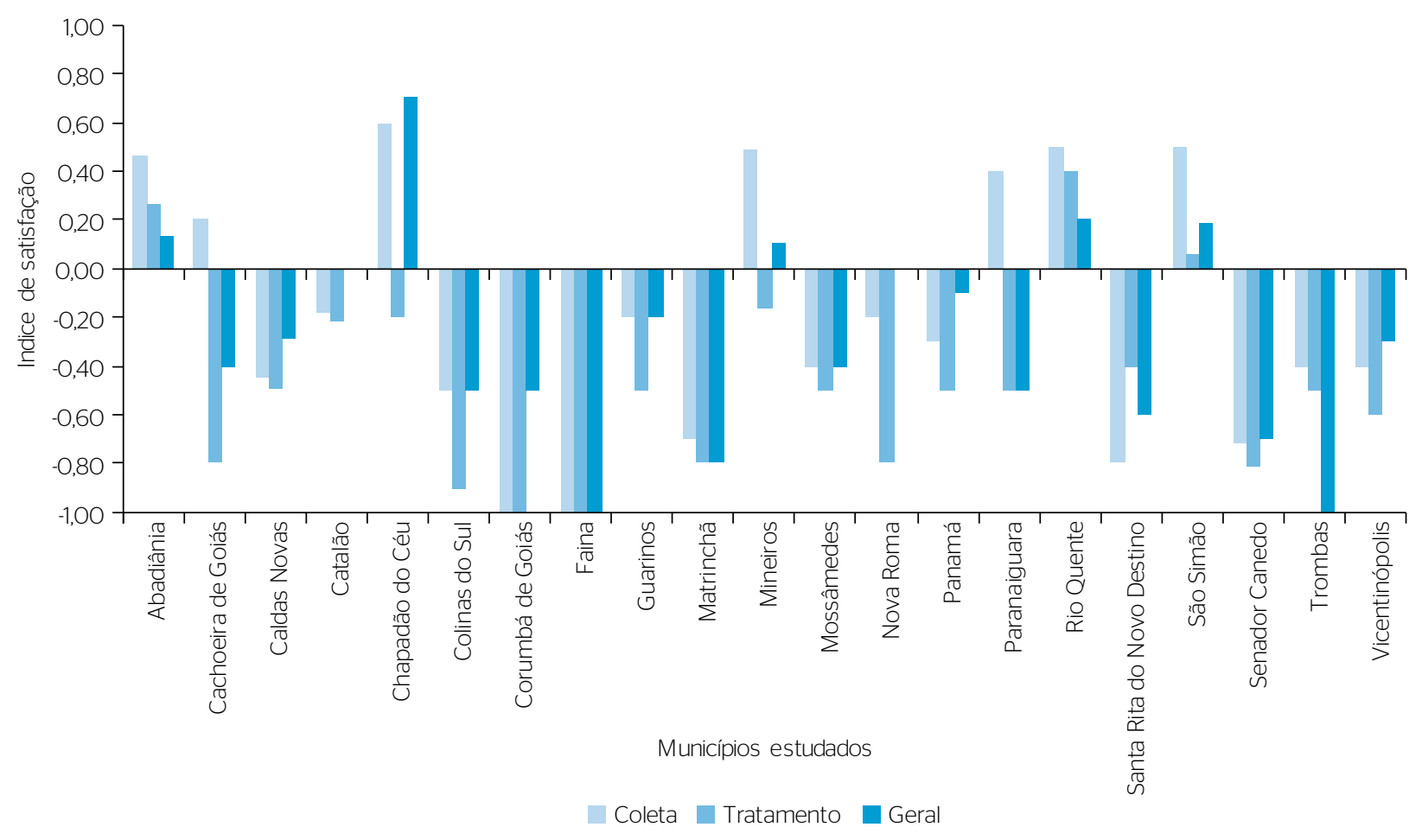

Figura 4 - Índice de satisfação em relação aos indicadores para o sistema de esgotamento sanitário. 
e 74\% (Tabela 1). Esse último índice representa os municípios de Abadiânia e Rio Quente. No primeiro, o esgoto, em 70\% do município, é coletado por rede coletora e encaminhado para a estação de tratamento de esgoto (ETE); no segundo, somente 25\% do município conta com rede coletora de esgoto, sendo essa concentrada na parte turística da região.

Na Figura 4, observa-se que os consumidores de Corumbá de Goiás e Faina estão $100 \%$ insatisfeitos com a coleta e o tratamento de esgoto. Eles não dispõem de rede coletora e lançam seus efluentes em fossas séptica ou negra, sendo a última a mais utilizada. Tal fato foi igualmente constatado por Giatti et al. (2004) na cidade de Iporanga, São Paulo. Nesta, 91\% das residências lançam seus esgotos em fossas, a maioria delas rudimentar. A fossa negra, além de não ser adequada, causa inconvenientes com relação à necessidade de limpeza, explosões, proliferação de vetores, presença de maus odores, entre outros problemas. Tais reclamações foram ouvidas durante a aplicação dos formulários nesses dois municípios.

A satisfação dos consumidores concernente aos serviços de esgotamento sanitário geral apresentou baixos níveis; apenas $28,6 \%$ dos municípios obtiveram satisfação acima de $50 \%$. Chapadão do Céu foi o município que apresentou a maior quantidade de consumidores satisfeitos. A rede coletora de esgoto desse município atende $67 \%$ da população, e o restante lança seus efluentes em fossas sépticas e rudimentares. Faina e Trombas se destacaram ao apresentarem $0 \%$ de satisfação, o que pode ser visualizado na Tabela 1 e na Figura 4. Ambos não contam com rede coletora de esgoto. Em Faina, houve a construção de uma ETE, porém não operante e em depreciação. Ademais, verificou-se que os consumidores confundem o sistema de coleta de esgoto com o de drenagem pluvial.

O índice de satisfação para essa vertente do saneamento básico, quando analisadas as respostas obtidas em todos os municípios pesquisados, foi de $-0,32$, em uma escala de $-1,0$ a $+1,0$. Ao analisar a realidade apresentada pelos municípios, as questões relacionadas ao esgotamento sanitário revelaram baixo índice de satisfação.

\section{Resíduos sólidos domiciliares}

No que tange à coleta dos RSD, em $85,7 \%$ dos municípios mais de $50 \%$ dos consumidores estão satisfeitos (Tabela 1). Nesse contexto, destaca-se o município de Trombas, que apresentou 100\% de consumidores satisfeitos. Por outro lado, em Colinas do Sul e Paranaiguara menos de $50 \%$ dos entrevistados estão satisfeitos. Nesses dois municípios, as principais reclamações referiam-se ao espalhamento dos resíduos nas ruas e calçadas no momento da coleta dos resíduos das lixeiras, podendo ser previstas ações de melhorias.

Em $85,7 \%$ dos municípios, o percentual de pessoas satisfeitas ficou igual ou acima de 50\% para o transporte dos RSD. Em Corumbá de Goiás, $100 \%$ dos entrevistados estão satisfeitos. O município de Trombas é o segundo melhor avaliado para esse quesito (Figura 5).

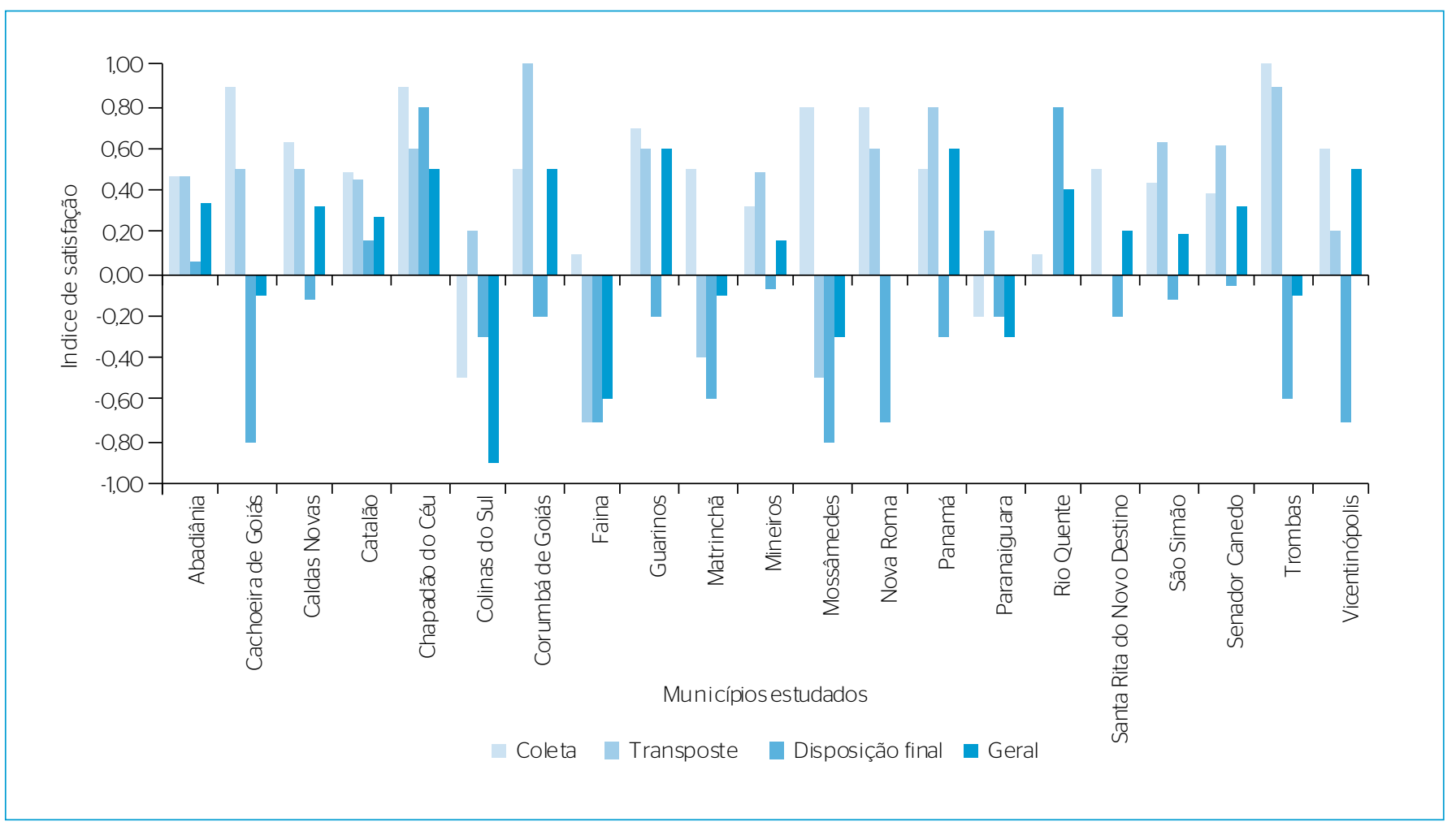

Figura 5 - Índice de satisfação em relação aos indicadores para os resíduos sólidos domiciliares. 
Importa mencionar que os problemas de derramamento e espalhamento de resíduos nas calçadas e em vias públicas foram objeto de reclamação por parte dos consumidores em todos os municípios.

Quanto à disposição final, apenas Abadiânia, Catalão, Chapadão de Céu e Rio Quente obtiveram percentual de satisfação acima de 50\%. Nos três últimos municípios, esses percentuais podem ser explicados pela presença de aterro sanitário. No entanto, em Abadiânia, verificou-se uma situação que evidencia a falta de conhecimento sobre a importância da disposição final dos resíduos: a presença de um lixão. Mesmo diante desse fato, mais de 50\% dos entrevistados estão satisfeitos com essa situação. Em 71,4\% dos municípios, os consumidores satisfeitos estão abaixo de 24\% (Tabela 1 e Figura 5). Isso se justifica pela presença de lixões, que, segundo a Lei $\mathrm{n}^{\circ}$ 12.305/2010, deveriam ter sido erradicados até agosto de 2014 (BRASIL, 2010). Como muitos municípios brasileiros não conseguiram se adequar ao Projeto de Lei $\mathrm{n}^{\circ}$ 2.289/2015 - tramitado no Senado e, atualmente, em tramitação na Câmara dos Deputados - , prorrogou-se o prazo para a disposição final ambientalmente adequada dos resíduos para o período de 2018 a 2021, dependendo do tipo do município (BRASIL, 2015).

Englobando todos os serviços de resíduos sólidos, 38,1\% dos municípios obtiveram percentuais de satisfação igual ou inferior a $50 \%$. Nesse quesito, nenhum município obteve percentual de satisfação acima de
$75 \%$ (Tabela 1). O menor índice de satisfação foi observado em Colinas do Sul, seguido por Faina (Figura 5). Observa-se ainda que o índice médio entre todos os entrevistados nos municípios pesquisados para os RSD foi de $+0,17$, na escala de $-1,0$ a $+1,0$. De maneira geral, os dados evidenciam maior satisfação para esse serviço em relação ao SES e à drenagem urbana.

\section{Drenagem urbana}

Acerca do sistema de drenagem urbana (SDU), 47,6\% dos municípios obtiveram índice de satisfação inferior a 50\% (representado pela escala zero na Figura 6), e nenhum obteve satisfação acima de 74\% (Tabela 1). Os municípios com os maiores índices de satisfação foram Chapadão do Céu e Rio Quente, o que pode ser explicado pela presença de rede coletora de água pluvial, que atende mais de $70 \%$ da população, e pela falta de ocorrência de inconvenientes decorrentes de problemas de drenagem. $O$ índice de satisfação médio para drenagem urbana, entre todos os municípios pesquisados, foi de $+0,02$, isto é, acima de $50 \%$ da população.

\section{Índice de satisfação}

As respostas obtidas foram analisadas conjuntamente, ou seja, 479 formulários, com 12 questões cada, totalizando 5.748 respostas.

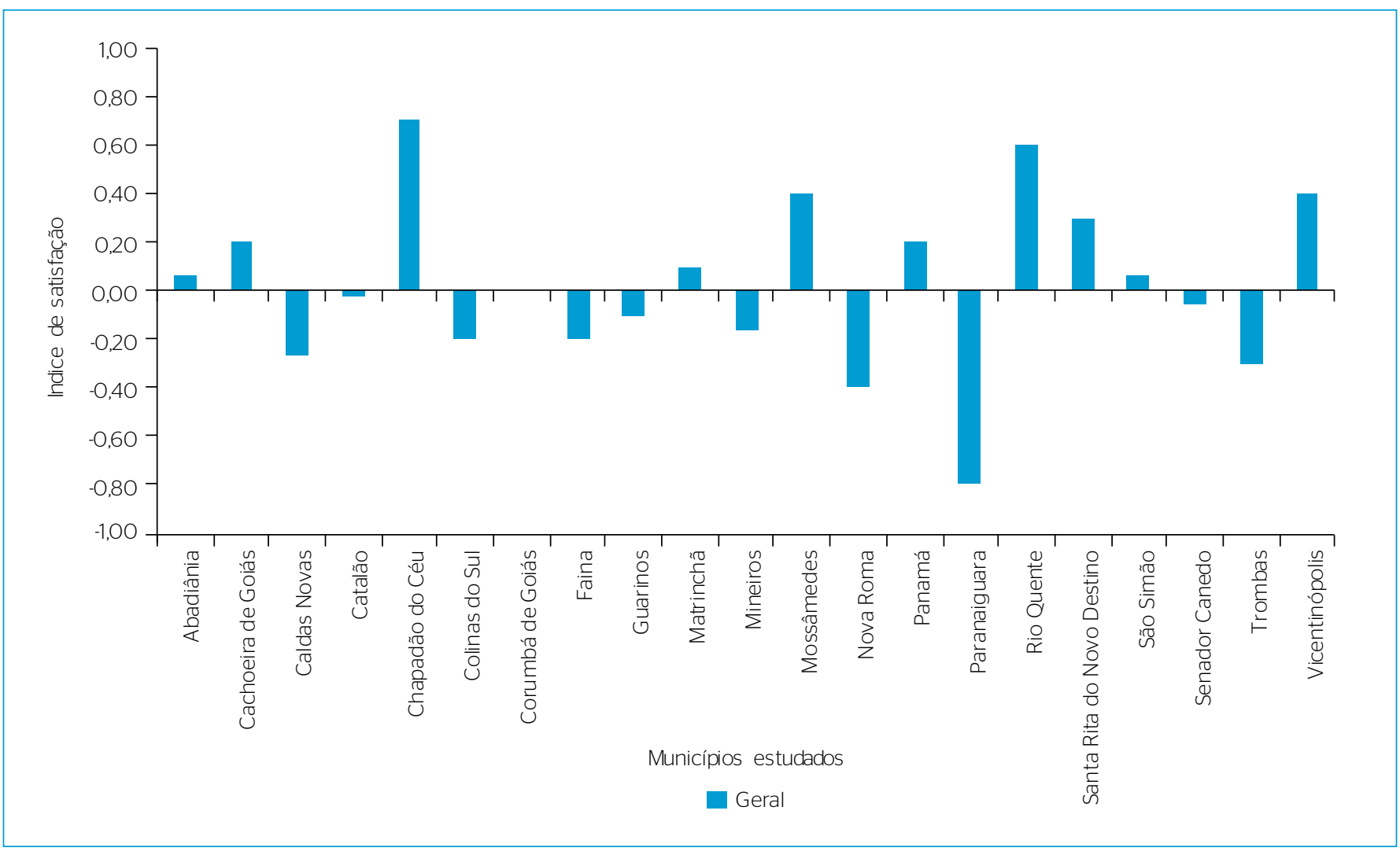

Figura 6 - Índice de satisfação em relação ao indicador para drenagem urbana. 
Os resultados encontrados foram estes: 2.585 respostas para satisfeitos; 1.833, insatisfeitos; 1.052, indiferentes; e 278 sem respostas. Houve um índice de satisfação geral em saneamento básico nos 21 municípios, variando de $-0,54 \mathrm{a}+0,63$, em uma escala de $-1,0 \mathrm{a}+1,0$. Faina foi o município que recebeu a pior avaliação $(-0,54)$, seguido de Matrinchã $(-0,25)$. O município de Chapadão do Céu e de Rio Quente foram os que obtiveram os melhores índices de satisfação, $+0,52$ e $+0,63$, respectivamente (Figura 7). Esses últimos dados refletem a realidade dos municípios, que apresentam qualidade nos serviços prestados.

A Análise de Cluster permitiu dividir os municípios em quatro grupos, conforme características similares com relação à percepção $\mathrm{e}$ às condições de saneamento. Os grupos foram enumerados de $1 \mathrm{a}$ 4. Nos grupos 1 e 4, estão os municípios com os melhores e os piores índices de satisfação, respectivamente. Nos grupos 2 e 3, encontram-se os municípios com índices intermediários, dos melhores para os piores, respectivamente. Na Tabela 2, pode ser observado o enquadramento de cada município em grupos, para o saneamento básico em geral, estando, ao lado, o índice de satisfação (Is), bem como o total de vezes ocupado em cada grupo na análise de Cluster. Dessa forma, é possível verificar quais áreas do saneamento básico os moradores dos municípios avaliaram como piores ou melhores.
Assim, a presente pesquisa pode se configurar como documento para consulta por parte dos gestores dos municípios analisados, a fim de fomentar propostas de melhorias para os seus respectivos sistemas de saneamento.

\section{CONCLUSÃO}

A satisfação e a percepção dos consumidores com relação aos sistemas de saneamento nem sempre estão ligadas à eficiência ou não desses sistemas. Isso pôde ser observado nos índices de satisfação acerca das características organolépticas da água em municípios que não realizam tratamento e naqueles em que os consumidores consideram aterro sanitário como uma prática incorreta, o que evidencia a importância da educação sanitária.

Verifica-se que o grau de insatisfação prevaleceu nas questões relacionadas à destinação dos resíduos sólidos e de esgoto, visto que esses sistemas, nos municípios estudados, foram os que apresentaram maiores deficiências. Desse modo, necessitam de intervenções, com vistas ao atendimento das necessidades da população.

Nesse contexto, além de recursos financeiros para a realização das melhorias, são necessários: trabalhos de conscientização com a população sobre a importância de se introduzir sistema de tratamento de

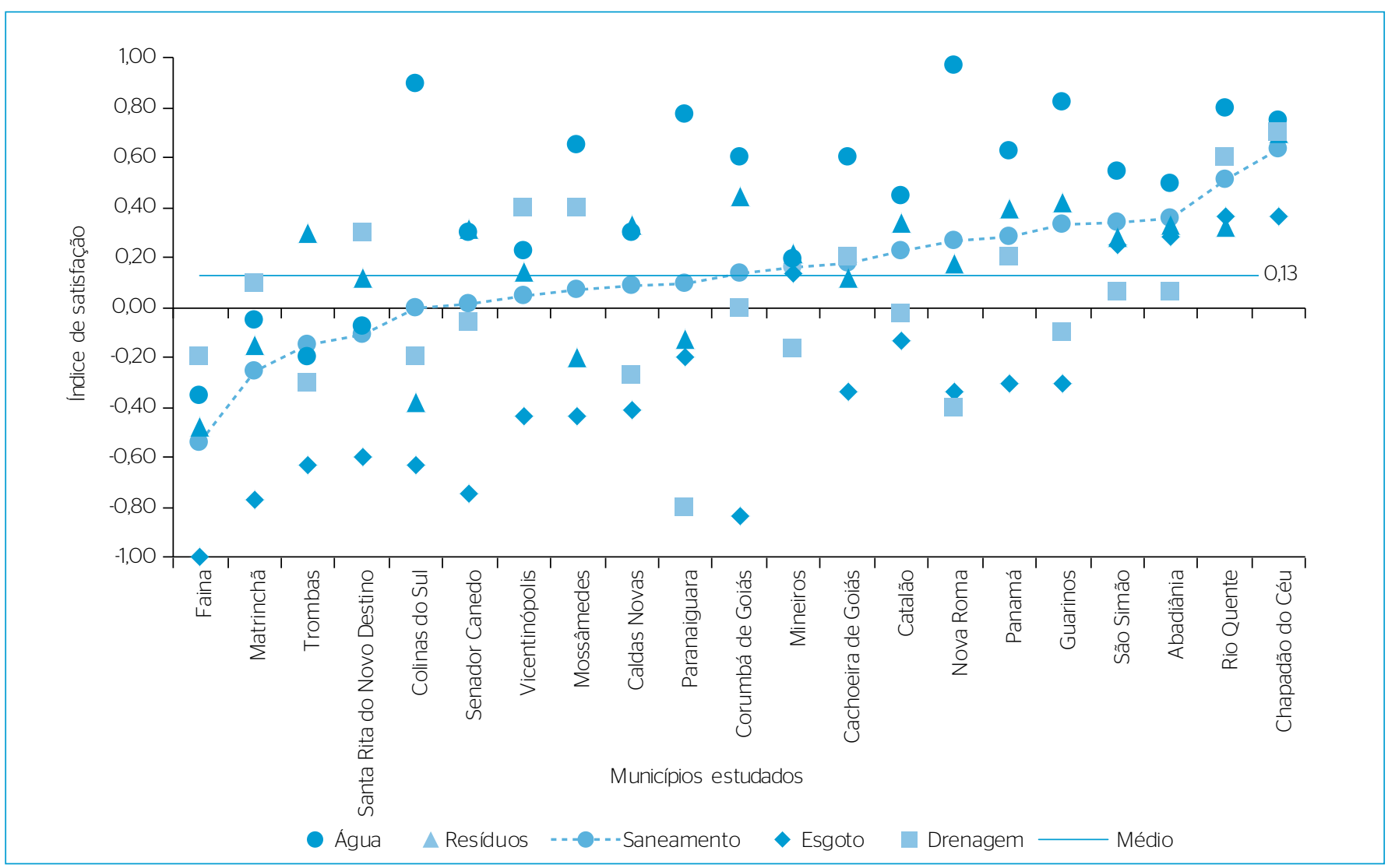

Figura 7 - Índice de satisfação para o saneamento como um todo e para as quatro vertentes isoladamente, além de um valor médio encontrado entre todos os municípios pesquisados. 
Tabela 2 - Enquadramento de cada município em grupos, para o saneamento básico, e o total de vezes ocupado em cada grupo, na análise de Cluster, para cada questão isoladamente.

\begin{tabular}{|c|c|c|c|c|c|c|c|c|c|c|c|c|c|c|c|c|c|c|c|c|c|c|}
\hline \multirow{3}{*}{ Município } & \multicolumn{4}{|c|}{ SAA } & \multicolumn{4}{|c|}{ SES } & \multicolumn{4}{|c|}{ RSD } & \multicolumn{4}{|c|}{ SDU } & \multicolumn{4}{|c|}{ Total } & \multirow{2}{*}{\multicolumn{2}{|c|}{$\begin{array}{l}\text { Saneamento } \\
\text { básico geral }\end{array}$}} \\
\hline & \multicolumn{4}{|c|}{ Grupos } & \multicolumn{4}{|c|}{ Grupos } & \multicolumn{4}{|c|}{ Grupos } & \multicolumn{4}{|c|}{ Grupos } & \multicolumn{4}{|c|}{ Grupos } & & \\
\hline & 1 & 2 & 3 & 4 & 1 & 2 & 3 & 4 & 1 & 2 & 3 & 4 & 1 & 2 & 3 & 4 & 1 & 2 & 3 & 4 & Is & Grupo \\
\hline Chapadão do Céu & 2 & 2 & & & 2 & 1 & & & 3 & 1 & & & 1 & & & & 8 & 4 & 0 & 0 & 0,63 & 1 \\
\hline Rio Quente & 2 & 2 & & & 3 & & & & 2 & & 1 & 1 & 1 & & & & 8 & 2 & 1 & 1 & 0,52 & 1 \\
\hline Abadiânia & & 2 & 2 & & 3 & & & & & 3 & 1 & & & 1 & & & 3 & 6 & 3 & 0 & 0,36 & 1 \\
\hline São Simão & & 4 & & & 2 & 1 & & & & 3 & 1 & & & 1 & & & 2 & 9 & 1 & 0 & 0,34 & 1 \\
\hline Guarinos & 2 & 2 & & & & 2 & 1 & & 1 & 3 & & & & & 1 & & 3 & 7 & 2 & 0 & 0,33 & 1 \\
\hline Panamá & & 4 & & & & 2 & 1 & & 2 & 1 & 1 & & & 1 & & & 2 & 8 & 2 & 0 & 0,28 & 1 \\
\hline Nova Roma & 4 & & & & 1 & 1 & & 1 & 1 & 1 & 1 & 1 & & & 1 & & 6 & 2 & 2 & 2 & 0,27 & 1 \\
\hline Catalão & & 3 & 1 & & 1 & 2 & & & & 3 & 1 & & & 1 & & & 1 & 9 & 2 & 0 & 0,23 & 2 \\
\hline Cachoeira de Goiás & 2 & 1 & 1 & & 1 & 1 & & 1 & 1 & 1 & 1 & 1 & & 1 & & & 4 & 4 & 2 & 2 & 0,18 & 2 \\
\hline Mineiros & & & 3 & 1 & 2 & 1 & & & & 3 & 1 & & & & 1 & & 2 & 4 & 5 & 1 & 0,16 & 2 \\
\hline Corumbá de Goiás & & 4 & & & & & 1 & 2 & 2 & 1 & 1 & & & 1 & & & 2 & 6 & 2 & 2 & 0,14 & 2 \\
\hline Paranaiguara & 2 & 2 & & & 1 & & 2 & & & 1 & 2 & 1 & & & & 1 & 3 & 3 & 4 & 2 & 0,10 & 2 \\
\hline Caldas Novas & & & 4 & & & 2 & 1 & & & 4 & & & & & 1 & & 0 & 6 & 6 & 0 & 0,09 & 2 \\
\hline Mossâmedes & 2 & 1 & 1 & & & 2 & 1 & & 1 & & 1 & 2 & 1 & & & & 4 & 3 & 3 & 2 & 0,08 & 2 \\
\hline Vicentinópolis & & & 3 & 1 & & 2 & 1 & & 1 & 1 & 1 & 1 & 1 & & & & 2 & 3 & 5 & 2 & 0,05 & 2 \\
\hline Senador Canedo & & & 4 & & & & 2 & 1 & & 3 & 1 & & & & 1 & & 0 & 3 & 8 & 1 & 0,02 & 2 \\
\hline Colinas do Sul & 3 & 1 & & & & 1 & 1 & 1 & & 1 & 1 & 2 & & & 1 & & 3 & 3 & 3 & 3 & 0,00 & 2 \\
\hline Santa Rita do Novo Destino & & & 3 & 1 & & & 3 & & & 2 & 2 & & & 1 & & & 0 & 3 & 8 & 1 & $-0,11$ & 3 \\
\hline Trombas & & & 1 & 3 & & 1 & 1 & 1 & 2 & & 2 & & & & 1 & & 2 & 1 & 5 & 4 & $-0,15$ & 3 \\
\hline Matrinchã & & 1 & & 3 & & & 1 & 2 & & & 3 & 1 & & 1 & & & 0 & 2 & 4 & 6 & $-0,25$ & 3 \\
\hline Faina & & & 1 & 3 & & & & 3 & & & & 4 & & & 1 & & $\mathrm{O}$ & 0 & 2 & 10 & $-0,54$ & 4 \\
\hline
\end{tabular}

SAA: sistema de abastecimento de água; SES: sistema de esgotamento sanitário; RSD: resíduos sólidos domiciliares; SDU: sistema de drenagem urbana; Is: índice de satisfação.

água nos municípios que ainda não dispõem dele; construção de fossas sépticas nas cidades em que não há rede coletora de esgoto; regularização das ligações dessas redes nas cidades que as possuem; acondicionamento dos RSD em sacos plásticos e lixeiras adequadas; e a participação dos programas de coleta seletiva, entre outras ações.

Esta pesquisa revela a importância da realização de trabalhos que identifiquem os problemas de saneamento no estado de Goiás, dando origem a bancos de dados importantes para o gerenciamento do saneamento e para a história do estado. Além de tratar das condições de saneamento, o presente estudo fez um levantamento acerca da satisfação e da opinião do consumidor diante desse serviço, conferindo caráter participativo à pesquisa.

Mesmo não sendo o objetivo desta pesquisa avaliar a influência política na realização de estudos de satisfação, faz-se necessário apontar o seu impacto na população. A forte atividade política ficou perceptível principalmente nos municípios de pequeno porte, em que foi encontrada dificuldade na aplicação dos formulários, pois os consumidores relacionavam a pesquisa com possíveis intrigas políticas e com a implantação de tarifa de água nos municípios em que esta não é cobrada.

Como já previsto por Marconi e Lakatos (2003), a utilização de formulário como instrumento de coleta de dados tem a vantagem de mostrar além do proposto por um estudo. Por outro lado, tem como desvantagem oferecer menor liberdade para se responder às questões, uma vez que o pesquisador fica frente a frente com o pesquisado.

Diante do exposto, entende-se que este estudo possibilitou verificar a satisfação de consumidores com relação aos serviços de saneamento prestados em alguns municípios do estado de Goiás. Com base nos resultados obtidos, os gestores dos órgãos municipais poderão ter acesso a dados que apontam quais aspectos causam maior insatisfação, tendo a possibilidade de intervir na situação. Ademais, ressalta-se que os estudos realizados na área de Saneamento Básico não devem cessar. Os municípios precisam diagnosticar os problemas sanitários que possuem, a fim de garantir ações de caráter preventivo e não imediato. 


\section{REFERÊNCIAS}

ADANK, M.; BUTTERWORTH, J.; GODFREY, S.; ABERA, M. (2O16) Looking beyond headline indicators: water and sanitation services in small towns in Ethiopia. Journal of Water Sanitation and Hygiene for Development, p. 1-12.

AKINBOADE, O.A.; KINFACK, E.C.; MOKWENA, M.P. (2O12) An analysis of citizen satisfaction with public service delivery in the Sedibeng district municipality of South Africa. International Journal of Social Economics, v. 39, n. 3, p. 182-199.

ALI, K.M.B; MOLLA, M.H.; FAISAL, M.M. (2014) Urban socioeconomic and environmental condition of hill tracts Bangladesh: a case study in Bandarban municipality. IOSR Journal of Humanities and Social Science, v. 19, n. 4, p. 36-44

ALVES, H.M.B. (2003) Uma abordagem de marketing à satisfação do aluno no ensino universitário público: índice, antessentes e consequências. 286p. Tese (Doutorado em Gestão) Departamento de Gestão e Economia, Universidade da Beira Interior, Covilhã, Portugal.

AL-QADERY, S. \& MUHIBBULLAH, M. (2008) People's perception on urban traffic congestion; a case study on Chittagong Metropolitan City, Bangladesh. Chittagong University Journal of Biological Sciences, v. 3, p. 149-160.

ARSESP - Agência Reguladora de Saneamento e Energia do Estado de São Paulo. (2013) Pesquisa de satisfação dos usuários residenciais dos serviços de água e esgoto de municípios do estado de São Paulo. São Paulo. Disponível em: <http://www.arsesp. sp.gov.br/ResultadoPesquisaSatisfacaoArquivo/Jales.pdf>. Acesso em: 17 out. 2014.

BADRI, M.; AL KHAILI, M.; AL MANSOORI, R.L. (2015) Quality of service, expectation, satisfaction and trust in public institutions: the Abu Dhabi citizen satisfaction survey. Asian Journal of Political Science, v. 23, n. 3, p. 420-447.

BRASIL. (1997) Ministério da Administração Federal e Reforma do Estado. Programa da qualidade e participação na administração pública. Brasília.

BRASIL. (2007) Institui sobre a Política Nacional de Saneamento Básico. Lei n.o 11.445, de 5 de janeiro de 2007. Estabelece diretrizes nacionais para o saneamento básico. Diário Oficial da União, Brasília.

BRASIL. (2010) Institui a Política Nacional de Resíduos Sólidos. Lei n. 0 12.305; altera a Lei n.0 9.605, de 12 de fevereiro de 1998; e dá outras providências. Diário Oficial da União, Brasília.

BRASIL. (2011) Ministério das Cidades. Secretaria Nacional de Saneamento Ambiental. Panorama do Saneamento Básico no Brasil. Volume II. Disponível em: <http://www.cidades.gov.br/ images/stories/ArquivosSNSA/PlanSaB/PANORAMA_Vol_2.pdf>. Acesso em: 11 mar. 2012
BRASIL. (2015) Câmara dos Deputados. Projeto de Lei do Senado n. 0 2.298, de 2014. Altera a Lei n. ${ }^{12.305 / 10, ~ q u e ~ i n s t i t u i ~ a ~ P o l i ́ t i c a ~}$ Nacional de Resíduos Sólidos. Prorroga o prazo para a disposição final ambientalmente adequada dos rejeitos de que trata o art. 54 da Lei n. ${ }^{0}$ 12.305, de 2 de agosto de 2010. Disponível em: <http://www2.camara.leg.br/proposicoesWeb/prop_mostrarinte gra;jsessionid=113C6A3005298BCFEB3406A947F180F9.propos icoesWeb1? codteor=1358710\&filename=PL+2289/2015>. Acesso em: 20 out. 2015.

DURAN, B.S. \& ODELL, P.L. (1974) Cluster analysis: a survey. Nova York: Springler. (Lecture notes in economics and mathematical systems).v. 100.

FERREIRA FILHO, S.S. \& ALVES, R. (2006) Técnicas de avaliação de gosto e odor em águas de abastecimento: método analítico, análise sensorial e percepção dos consumidores. Engenharia Sanitária e Ambiental, Rio de Janeiro, v. 11, n. 4, p. 362-370.

GALVÃO JÚNIOR, A.C. \& PAGANINI, W.S. (2009) Aspectos conceituais da regulação dos serviços de água e esgoto no Brasil. Engenharia Sanitária e Ambiental, Rio de Janeiro, v. 14, n. 1, p. 79-88.

GIATTI, L.L.; ROCHA, A.A.; SANTOS, F.A.; BITENCOURT, S.C.; PIERONI, S.R.M. (2004) Condições de saneamento básico em Iporanga, Estado de São Paulo. Saúde Pública, São Paulo, v. 38, n. 4, p. 571-577.

IBGE - Instituto Brasileiro de Geografia e Estatística. (2010) Série Cidades. Brasília.

JARDINE, C.G.; GIBSON, N.; HRUDEY, S.E. (1999) Detection of odour and health risk perception of drinking water. Water Science and Technology, v. 40, n. 6, p. 91-98.

KUHNEN, A.; IMPROTA, R.L.; SILVEIRA, S.M. (2009) Comportamento humano e recursos naturais: qualidade e disponibilidade da água avaliadas pelos usuários. Psicologia: Teoria e Pesquisa, Brasília, v. 25, n. 3, p. 453-460.

LAGE, L.M.S. (2008) Qualidade e satisfação nos serviços públicos: o caso de uma empresa municipal - EMARVR. Dissertação (Mestrado em Gestão Pública e Autárquica) - Universidade de Trás-os-Montes e Alto Douro, Vila Real, Portugal.

LUIZ, A.J.B.; FORMAGGIO, A.R.; EPIPHANIO, J.C.N.; TOLEDO, J.M.A.; GOLTZ, E.; BRANDÃO, D. (2012) Estimativa amostral objetiva de área plantada regional, apoiada em imagens de sensoriamento remoto. Pesquisa Agropecuária Brasileira, v. 47, n. 9, p. 1279-1287.

MAJUMDER, A.K.; HOSSAIN, M.E.; ISLAM, M.N.; SARWAR, M.I. (2OO7) Urban environmental quality mapping: a perception study on Chittagong Metropolitan City. Kathmandu University Journal of Science, Engineering and Technology, v. 3, n. 2, p. 35-48.

MARCONI, M. \& LAKATOS, E. (1992) Metodologia do trabalho científico. $4^{a}$ ed. São Paulo: Atlas. 
MARCONI, M. \& LAKATOS, E. (2003) Fundamentos de metodologia científica. 5a ed. São Paulo: Atlas. 214p.

MARTINI, P.C.L;; FRANKE, E.A.; VEIGA, R.C. (1999) Percepção da qualidade da água pelos usuários da grande Florianópolis. In: Simpósio Brasileiro de Recursos Hídricos, 13. Anais eletrônicos...

MILAGRES, V.R. \& SAYAGO, D.A.V. (2O12) Qualidade da água e Doenças Relacionadas ao Saneamento Ambiental Inadequado (DRSAI): uma abordagem perceptiva com os moradores do Distrito Taquaruçu, Palmas (TO). Revista Brasileira de Geografia Física, v. 5, n. 6, p. 1317-1332.

MOGAMI, S. (2013) Perfil do setor de saneamento. Hydro, São Paulo, ano 7, n. 79.

MONTENEGRO, M.H.F. \& COSTA, S.S. (1999) Política da qualidade e sistema de gestão CAESB - A ênfase na satisfação dos consumidores. In: Congresso Brasileiro de Engenharia Sanitária e Ambiental, 20. Anais eletrônicos... ABES, 1Op.

NEYMAN, J. (1934) On two different aspects of the representative method: The method of stratified sampling and the method of purposive selection. Journal of the Royal Statistical Society, v. 97, n.4, p.558-606.

ORTIZ-CORREA, J.S.; RESENDE FILHO, M.; DINAR, A. (2O16) Impact of access to water and sanitation services on educational attainment. Water Resources and Economics, v. 14, p. 31-43.

PÉLLICO NETTO, S. \& SANQUETTA, C.R. (1997) Ganhos de precisão na alocação ótima em estratificação volumétrica de florestas naturais e plantações florestais. Floresta, v. 27, n. 12, p. 71-82.

QUEIROZ, JT.M.; HELLER, L.; SILVA, S.R. (2009) Análise da correlação de ocorrência da doença diarreica aguda com a qualidade da água para consumo humano no município de Vitória-ES. Saúde e Sociedade, São Paulo, v. 18, n. 3, p. 479-489.
RIBEIRO, E.M. \& GALIZONI, F.M. (2003) Água, população rural e políticas de gestão: o caso do vale do Jequitinhonha, Minas Gerais. Ambiente \& Sociedade, v. 5-6, n. 2-1, p. 129-146.

ROCHA, C.M.B.M.; RODRIGUES, L.S.; COSTA, C.C.; OLIVEIRA, P.R.; SILVA, I.J; JESUS, É.F.M.; ROLIM, R.G. (2006) Avaliação da qualidade da água e percepção higiênico-sanitária na área rural de Lavras, Minas Gerais, Brasil, 1999-2000. Cadernos de Saúde Pública, Rio de Janeiro, v. 22, n. 9, p. 1967-1978.

ROSSI, C.A.V. \& SLONGO, L.A. (1998) Pesquisa de satisfação de clientes: o estado-da-arte e proposição de um método brasileiro. Revista de Administração Contemporânea, v. 2, n. 1, p. 101-125.

SARWAR, M.I; CHOWDHURY, M.A.T.; MUHIBBULLAH, M. (2006) Quality of urban neighborhood environment: a case study of resident's perception in Chittagong City, Bangladesh. Trends in Applied Sciences Research, v. 1, p. 248-258.

SILVA, S.R.; HELLER, L.; VALADARES, J.C.; CAIRNCROSS, S. (2009) O cuidado domiciliar com a água de consumo humano e suas implicações na saúde: percepções de moradores em Vitória (ES). Engenharia Sanitária e Ambiental, Rio de Janeiro, v. 14, n. 4 , p. 521-532.

VARELA, L.H.F. (2016) Desafios ao direito humano à água e à sustentabilidade dos serviços em Santa Cruz, Cabo Verde. Ambiente \& Sociedade, v. 19, n. 1, p. 209-228.

VON SPERLING, T.L. \& VON SPERLING, M. (2013) Proposição de um sistema de indicadores de desempenho para avaliação da qualidade dos serviços de esgotamento sanitário. Engenharia Sanitária e Ambiental, Rio de Janeiro,v. 18, n. 4, p. 313-322.

YEH, S.H. \& LEE, S.T. (1975) Satisfaction of living condition. In: YEN, S.H. (Ed.). Public housing in Singapore. Singapore: Singapore University Press. 